\title{
Gas Chromatography Electron Ionization Mass Spectral Analysis of Thio Analogues of Pyrimidine Bases: 5-Bromo-2,4-di-o-(m- and $p$-) chloro- (bromo-)benzylthiouracils and 6-methyluracils
}

\author{
G. Bartkowiak, E. Wyrzykiewicz, and G. Schroeder \\ Faculty of Chemistry, Adam Mickiewicz University, Grunwaldzka 6, 60-780 Poznań, Poland \\ Correspondence should be addressed to G. Bartkowiak, gbartkow@amu.edu.pl \\ Received 14 July 2011; Accepted 30 September 2011 \\ Academic Editor: Hans Riesen
}

Copyright (c) 2012 G. Bartkowiak et al. This is an open access article distributed under the Creative Commons Attribution License, which permits unrestricted use, distribution, and reproduction in any medium, provided the original work is properly cited.

\begin{abstract}
Electron ionization (EI) mass spectral fragmentation routes of twelve 5-bromo-2,4-di-o-( $m$ - and $p$-) chloro- (bromo-)benzylthiouracils and 6-methyluracils are investigated. The compounds studied are analyzed using gas chromatography/mass spectrometry (GC/MS). Fragmentation pathways, whose elucidation is assisted by accurate mass measurements and metastable transitions, are discussed. Correlation between the abundances of the selected fragment ions of the compounds investigated is discussed. The data obtained make grounds for distinction of structural isomers.
\end{abstract}

\section{Introduction}

Thio derivatives of pyrimidine bases are of interest because of their biological and pharmacological activities, for example, as minor components of t-RNA or as antithyroidal and anticancer drugs as well as sedatives [1-7]. Essential role in biological systems play compounds, which contain 5-bromopyrimidine moiety, like 5-bromouracil and 5bromouridine. It is well known that these compounds are mutagenic [8-10] and able to replace thymine residue in the DNA molecule. On the other hand, C-5 bromo group is a hydrophobic substituent having also electron-negative properties, very important for anaesthetic and anticonflict activities [11]. The presence of benzyl group also influences the activity of pyrimidine derivatives, for example, the pyrimidine thioethers with 2-benzylthio substituent have been reported as a novel nonnucleoside HIV-1 reverse transferase inhibitors (NNRTIs) with activity against BHAP-resistant HIV [12, 13]. Because of biological importance of the modified thio analogues of pyrimidine bases, much attention has been devoted to recognize their properties. Mass spectrometry continues to be a convenient and effective method for determination of nature of covalent modifications to thio analogues of nucleobases and for distinction of structural isomers [14-17]. The mass spectral behavior of modified derivatives of thionucleobases, for example, 2-benzylthio and 4-benzylthiouracils which may appear in the gas phase in various tautomeric forms has been studied previously. However, to the best of our knowledge, no work has been published about the mass spectrometric behavior of fully aromatic 2,4-dibenzylthio-5-bromouracils. The hereby presented study of mass fragmentation of the title compounds were undertaken to examine the influence of C-5 bromo substitution in pyrimidine ring on their EI mass fragmentation.

Isomeric organic compounds discrimination is a challenging task for mass spectrometrists because of the identical molecular masses and similar fragmentation pathways of these species. However, differences in the nature and electronic effects of substituents, depending on their location in the molecule, lead to different stabilization possibilities and influence the kinetics of mass dissociation of molecular and fragment ions. These factors are strongly reflected by the abundances of ions in the electron-ionization mass spectra of such molecules. Comparison of the abundances of selected fragment and molecular ions reveals the preferences of the molecule's breakup and often allows isomers differentiation $[18,19]$.

The aim of this investigation was to elucidate the EI mass spectrometric fragmentations of 5-bromo-2,4-di-o( $m$ - and $p$-) chloro- (bromo-)benzylthiouracils 1-6 and 


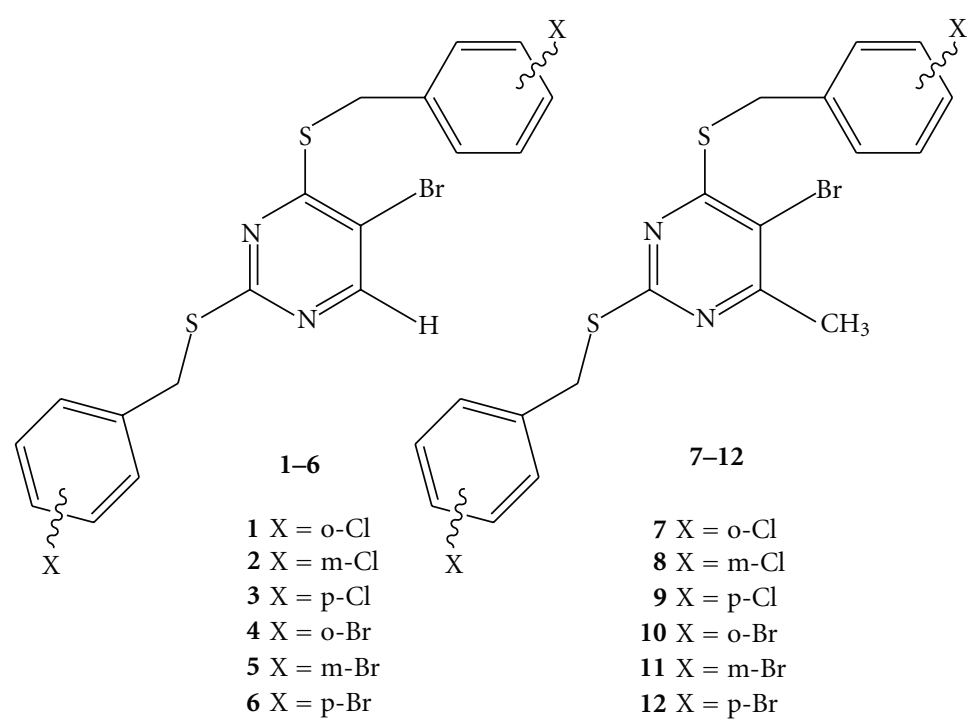

Figure 1: 5-Bromo-2,4-di-o -( $m$ - and $p$-)chloro- (bromo-)benzylthiouracils 1-6 and 5-bromo-2,4-di-o - $(m-$ and $p$-)chloro-(bromo- $)$ benzylthio-6-methyluracils 7-12.

5-bromo-2,4-di-o- ( $m$ - and $p$-) chloro- (bromo-)benzylthio6-methyluracils 7-12 (presented in Figure 1) and to find out whether it is possible to differentiate isomeric species in this group of compounds on the basis of their EI mass spectra. A comparison was made of the values of coefficients $\mu$, that is, the ratios of the abundances of selected ions, fragment or molecular, to those of other characteristic ions. This procedure has been previously used in our laboratory [20-23].

To ensure that the EI mass spectra of 1-12 come from the really pure compounds, all the above 2,4-dithiouracil derivatives obtained have been submitted to gas chromatography combined with electron ionization mass spectrometry.

\section{Experimental}

All compounds 1-12 were analyzed on a gas chromatograph linked with a mass spectrometer Varian 4000 GC/MS. Gas chromatography conditions were GC CP3800 equipped with column VF-5 ms $(30 \mathrm{~m} \times 0,25 \mathrm{~mm} \times 0,39 \mathrm{~mm})$, carrier gas helium, $1 \mathrm{~mL} \mathrm{~min}{ }^{-1}$, injector type 1177 , split $1: 50$, temperature $250^{\circ} \mathrm{C}$. Low-resolution mass spectra were taken from the individual chromatographic peaks after GC isolation/purification of compounds studied. The mass spectrometer with internal ion trap worked with electron ionization at the ion source temperature $220^{\circ} \mathrm{C}$ and ionization energy $70 \mathrm{eV}$. The measurements were made in the mass range $40-800 \mathrm{~m} / \mathrm{z}$. High-resolution mass spectra and metastable transitions were recorded on an AMD-Intectra GmbH (D-27243 Harpstedt, Germany) Model 402 twosector mass spectrometer (ionizing energy $70 \mathrm{eV}$, accelerating voltage $8 \mathrm{kV}$, resolution 10.000 at $10 \%$ valley). Samples were introduced using a direct insertion probe at a source temperature $\sim 160^{\circ} \mathrm{C}$. The elemental compositions of the ions were determined by peak matching relative to perfluorokerosene. All masses measured agreed with those of the compositions given in Tables 1 and 2 within $\pm 2 \mathrm{ppm}$. Data from the first field free region, recorded using constant $B / E$ and $B^{2} / E$ linked scans, were obtained.

The values of $\mu$ (see further in the text) were calculated as averages of three measurements (Table 3 ) . Compounds 1-12 were obtained according to literature [24].

\section{Results and Discussion}

On the basis of the low-resolution EI mass spectra as well as $B / E$ and $B^{2} / E=$ const linked scan spectra and exact mass measurements (Tables 1 and 2), the principal EI mass fragmentation routes of compounds 1-12 are interpreted as shown in Scheme 1. Bearing in mind that the structures of fragment ions are always speculative, only elemental compositions for the fragment ions are given. The electronionization mass fragmentation pathways of $\mathrm{M}^{+\bullet}$ (a) ions of 1-12 confirmed by the metastable transitions observed in $B / E$ and $B^{2} / E$ linked scan spectra are labeled with an asterisk in Scheme 1. The abundances of the selected important ions are shown in Tables 1 and 2. It should be emphasized that theoretical isotopic patterns are much more complex than those shown in Tables 1 and 2, but, for clarity, only the main, most intense, isotopic peaks have been taken into account. The isotopic distribution of some ions, for example, $\mathbf{b}\left(\mathrm{M}^{+\cdot}\right.$ $\cdot \mathrm{SH})$ and $\mathbf{c}\left(\mathrm{M}^{+\cdot}-{ }^{\bullet} \mathrm{Cl}\right)$ of compounds $\mathbf{1}-\mathbf{3}$ are disturbed due to their signals overlapping.

As an example, theoretical isotopic pattern $[\mathrm{m} / \mathrm{z}$ (relative intensity), the most intense bolded] of ion $\mathbf{b}$ $\left(\mathrm{C}_{18} \mathrm{H}_{12} \mathrm{~N}_{2} \mathrm{SBrCl}_{2}\right)$ is

$$
\begin{aligned}
& \text { 437(59.2\%)/438(12.5\%)/439(100\%) } \\
& \quad / 440(20.9 \%) / 441(50 \%) / 442(10.2 \%) / 443(9 \%)
\end{aligned}
$$


TABLE 1: Elemental compositions and relative abundances of the ion peaks in the spectra of 1-6 according to the high-resolution data.

\begin{tabular}{|c|c|c|c|c|c|c|c|c|}
\hline \multirow{2}{*}{ Ion } & \multirow{2}{*}{$\mathrm{m} / \mathrm{z}$} & \multirow{2}{*}{$\begin{array}{l}\text { Elemental } \\
\text { composition }\end{array}$} & \multicolumn{6}{|c|}{$\%$ relative abundance (\%RA) } \\
\hline & & & 1 & 2 & 3 & 4 & 5 & 6 \\
\hline $\mathbf{M}^{+\bullet}$ & $470 / 472 / 474$ & $\mathrm{C}_{18} \mathrm{H}_{13} \mathrm{~N}_{2} \mathrm{~S}_{2} \mathrm{Cl}_{2} \mathrm{Br}$ & $13 / 20 / 13$ & $23 / 42 / 23$ & $12 / 24 / 16$ & - & - & - \\
\hline a & $558 / 560 / 562 / 564$ & $\mathrm{C}_{18} \mathrm{H}_{13} \mathrm{~N}_{2} \mathrm{~S}_{2} \mathrm{Br}_{3}$ & - & - & - & $9 / 30 / 23 / 8$ & $15 / 31 / 34 / 17$ & $13 / 37 / 38 / 13$ \\
\hline \multirow{2}{*}{$\mathbf{b}[\mathbf{a}-\cdot \mathrm{SH}]$} & $437 / 439 / 441$ & $\mathrm{C}_{18} \mathrm{H}_{12} \mathrm{~N}_{2} \mathrm{SCl}_{2} \mathrm{Br}$ & $27 / 14 / 3$ & $6 / 14 / 5$ & $6 / 5 / 4$ & & & \\
\hline & $525 / 527 / 529 / 531$ & $\mathrm{C}_{18} \mathrm{H}_{12} \mathrm{~N}_{2} \mathrm{SBr}_{3}$ & & & & $1 / 5 / 6 / 2$ & $6 / 7 / 12 / 5$ & $2 / 10 / 9 / 3$ \\
\hline \multirow{2}{*}{$\mathbf{c}\left[\mathbf{a}-{ }^{\cdot} \mathbf{X}\right]$} & $435 / 437 / 439$ & $\mathrm{C}_{18} \mathrm{H}_{13} \mathrm{~N}_{2} \mathrm{~S}_{2} \mathrm{ClBr}$ & $21 / 27 / 14$ & $0.6 / 6 / 14$ & $0.9 / 6 / 5$ & & & \\
\hline & $479 / 481 / 483$ & $\mathrm{C}_{18} \mathrm{H}_{13} \mathrm{~N}_{2} \mathrm{~S}_{2} \mathrm{Br}_{2}$ & & & & $25 / 44 / 27$ & $6 / 14 / 9$ & $2 / 2 / 2$ \\
\hline \multirow{2}{*}{$\mathbf{d}[\mathbf{a}-\cdot \mathrm{SH}-\cdot \mathrm{X}]$} & $402 / 404 / 406$ & $\mathrm{C}_{18} \mathrm{H}_{12} \mathrm{~N}_{2} \mathrm{SClBr}$ & $3 / 4 / 1$ & $2 / 5 / 3$ & $2 / 2 / 3$ & - & - & - \\
\hline & $446 / 448 / 450$ & $\mathrm{C}_{18} \mathrm{H}_{12} \mathrm{~N}_{2} \mathrm{SBr}_{2}$ & - & - & - & $5 / 18 / 6$ & $7 / 11 / 4$ & $5 / 14 / 4$ \\
\hline \multirow{2}{*}{$\mathbf{d}^{\prime}[\mathbf{a}-\cdot \mathrm{SH}-\mathrm{HX}]$} & $401 / 403 / 405$ & $\mathrm{C}_{18} \mathrm{H}_{11} \mathrm{~N}_{2} \mathrm{SClBr}$ & $5 / 7 / 3$ & $5 / 10 / 4$ & $3 / 8 / 4$ & & & \\
\hline & $445 / 447 / 449$ & $\mathrm{C}_{18} \mathrm{H}_{11} \mathrm{~N}_{2} \mathrm{SBr}_{2}$ & & & & $2 / 12 / 3$ & $10 / 21 / 11$ & $13 / 27 / 15$ \\
\hline \multirow{2}{*}{ e } & $345 / 347 / 349$ & $\mathrm{C}_{11} \mathrm{H}_{7} \mathrm{~N}_{2} \mathrm{~S}_{2} \mathrm{ClBr}$ & $18 / 25 / 9$ & $32 / 42 / 14$ & $21 / 24 / 7$ & - & - & - \\
\hline & $389 / 391 / 393$ & $\mathrm{C}_{11} \mathrm{H}_{7} \mathrm{~N}_{2} \mathrm{~S}_{2} \mathrm{Br}_{2}$ & - & - & - & $13 / 54 / 18$ & $25 / 61 / 38$ & $27 / 48 / 27$ \\
\hline $\mathrm{f}\left[\mathrm{e}-{ }^{\bullet} \mathrm{X}\right]$ & $310 / 312$ & $\mathrm{C}_{11} \mathrm{H}_{7} \mathrm{~N}_{2} \mathrm{~S}_{2} \mathrm{Br}$ & $19 / 20$ & $5 / 13$ & $1 / 9$ & $53 / 68$ & $10 / 13$ & $6 / 6$ \\
\hline \multirow{2}{*}{ g } & $125 / 127$ & $\mathrm{C}_{7} \mathrm{H}_{6} \mathrm{Cl}$ & $100 / 36$ & $100 / 33$ & $100 / 33$ & - & - & - \\
\hline & $169 / 171$ & $\mathrm{C}_{7} \mathrm{H}_{6} \mathrm{Br}$ & - & - & - & $100 / 99$ & $72 / 70$ & $99 / 100$ \\
\hline h & 90 & $\mathrm{C}_{7} \mathrm{H}_{6}$ & 11 & 15 & 7 & 99 & 100 & 79 \\
\hline $\mathbf{j}$ & 89 & $\mathrm{C}_{7} \mathrm{H}_{5}$ & 58 & 58 & 42 & 85 & 73 & 72 \\
\hline
\end{tabular}

TABLE 2: Elemental compositions and relative abundances of the ion peaks in the spectra of 7-12 according to the high-resolution data.

\begin{tabular}{|c|c|c|c|c|c|c|c|c|}
\hline \multirow{2}{*}{ Ion } & \multirow{2}{*}{$\mathrm{m} / \mathrm{z}$} & \multirow{2}{*}{$\begin{array}{l}\text { Elemental } \\
\text { composition }\end{array}$} & \multicolumn{6}{|c|}{$\%$ relative abundance (\%RA) } \\
\hline & & & 7 & 8 & 9 & 10 & 11 & 12 \\
\hline $\mathbf{M}^{+\bullet}$ & $484 / 486 / 488$ & $\mathrm{C}_{19} \mathrm{H}_{15} \mathrm{~N}_{2} \mathrm{~S}_{2} \mathrm{Cl}_{2} \mathrm{Br}$ & $20 / 41 / 24$ & $25 / 48 / 24$ & $21 / 33 / 16$ & - & - & - \\
\hline $\mathbf{a}$ & $572 / 574 / 576 / 578$ & $\mathrm{C}_{19} \mathrm{H}_{15} \mathrm{~N}_{2} \mathrm{~S}_{2} \mathrm{Br}_{3}$ & - & - & - & $17 / 54 / 53 / 17$ & $13 / 44 / 49 / 20$ & $14 / 35 / 44 / 18$ \\
\hline \multirow{2}{*}{$\mathbf{b}[\mathbf{a}-\cdot \mathrm{SH}]$} & $451 / 453 / 455$ & $\mathrm{C}_{19} \mathrm{H}_{14} \mathrm{~N}_{2} \mathrm{SCl}_{2} \mathrm{Br}$ & $12 / 9 / 4$ & $10 / 14 / 7$ & $7 / 10 / 4$ & & & \\
\hline & $539 / 541 / 543 / 545$ & $\mathrm{C}_{19} \mathrm{H}_{14} \mathrm{~N}_{2} \mathrm{SBr}_{3}$ & & & & $3 / 5 / 9 / 3$ & $4 / 19 / 15 / 6$ & $2 / 10 / 12 / 4$ \\
\hline \multirow{2}{*}{$\mathbf{c}\left[\mathbf{a}-{ }^{\bullet} \mathbf{X}\right]$} & $449 / 451 / 453$ & $\mathrm{C}_{19} \mathrm{H}_{15} \mathrm{~N}_{2} \mathrm{~S}_{2} \mathrm{ClBr}$ & $3 / 12 / 9$ & $1 / 10 / 14$ & $0.1 / 7 / 10$ & & & \\
\hline & $493 / 495 / 497$ & $\mathrm{C}_{19} \mathrm{H}_{15} \mathrm{~N}_{2} \mathrm{~S}_{2} \mathrm{Br}_{2}$ & & & & $6 / 15 / 11$ & $12 / 23 / 8$ & $3 / 5 / 3$ \\
\hline \multirow{2}{*}{$\mathbf{d}\left[\mathbf{a}--^{\cdot S H}-{ }^{\cdot} \mathrm{X}\right]$} & $416 / 418 / 420$ & $\mathrm{C}_{19} \mathrm{H}_{14} \mathrm{~N}_{2} \mathrm{SClBr}$ & $4 / 4 / 3$ & $1 / 4 / 2$ & $1 / 1 / 1$ & & & \\
\hline & $460 / 462 / 464$ & $\mathrm{C}_{19} \mathrm{H}_{14} \mathrm{~N}_{2} \mathrm{SBr}_{2}$ & & & & $9 / 19 / 9$ & $4 / 9 / 1$ & $2 / 11 / 6$ \\
\hline \multirow{2}{*}{$d^{\prime}[\mathbf{a}-\mathrm{SH}-\mathrm{HX}]$} & $415 / 417 / 419$ & $\mathrm{C}_{19} \mathrm{H}_{13} \mathrm{~N}_{2} \mathrm{SClBr}$ & $3 / 6 / 2$ & $4 / 5 / 4$ & $1 / 3 / 3$ & & & \\
\hline & $459 / 461 / 463$ & $\mathrm{C}_{19} \mathrm{H}_{13} \mathrm{~N}_{2} \mathrm{SBr}_{2}$ & & & & $5 / 10 / 9$ & $8 / 18 / 13$ & $3 / 13 / 10$ \\
\hline \multirow{2}{*}{ e } & $359 / 361 / 363$ & $\mathrm{C}_{12} \mathrm{H}_{9} \mathrm{~N}_{2} \mathrm{~S}_{2} \mathrm{ClBr}$ & $31 / 33 / 14$ & $54 / 78 / 22$ & $28 / 46 / 12$ & - & - & - \\
\hline & 403/405/407 & $\mathrm{C}_{12} \mathrm{H}_{9} \mathrm{~N}_{2} \mathrm{~S}_{2} \mathrm{Br}_{2}$ & 一 & 一 & 一 & $48 / 81 / 44$ & $52 / 100 / 57$ & $35 / 72 / 44$ \\
\hline \multirow{2}{*}{$f\left[e-{ }^{\bullet} X\right]$} & \multirow{2}{*}{$324 / 326$} & \multirow{2}{*}{$\mathrm{C}_{12} \mathrm{H}_{9} \mathrm{~N}_{2} \mathrm{~S}_{2} \mathrm{Br}$} & $18 / 18$ & $2 / 13$ & $1 / 5$ & - & - & - \\
\hline & & & - & - & - & $70 / 70$ & $12 / 10$ & $12 / 11$ \\
\hline \multirow{2}{*}{ g } & $125 / 127$ & $\mathrm{C}_{7} \mathrm{H}_{6} \mathrm{Cl}$ & $100 / 31$ & $100 / 34$ & $100 / 33$ & - & - & - \\
\hline & $169 / 171$ & $\mathrm{C}_{7} \mathrm{H}_{6} \mathrm{Br}$ & - & - & - & $89 / 91$ & $73 / 70$ & $98 / 95$ \\
\hline h & 90 & $\mathrm{C}_{7} \mathrm{H}_{6}$ & 13 & 11 & 9 & 100 & 85 & 100 \\
\hline $\mathbf{j}$ & 89 & $\mathrm{C}_{7} \mathrm{H}_{5}$ & 57 & 66 & 41 & 81 & 76 & 94 \\
\hline
\end{tabular}

TABLE 3: Values of coefficients $\mu$ (definitions in the text) for 5-bromo-2,4-di- $o$ - ( $m$ - and $p$-) chloro- (bromo)benzylthiouracils 1-12.

\begin{tabular}{|c|c|c|c|c|c|c|c|c|c|c|c|c|}
\hline \multirow{2}{*}{$\mu$} & \multicolumn{12}{|c|}{ Comp } \\
\hline & 1 & 2 & 3 & 4 & 5 & 6 & 7 & 8 & 9 & 10 & 11 & 12 \\
\hline$\mu_{1}=\mathbf{a} / \mathbf{g}$ & 0.20 & 0.42 & 0.24 & 0.30 & 0.47 & 0.38 & 0.41 & 0.48 & 0.33 & 0.60 & 0.67 & 0.45 \\
\hline$\mu_{2}=\mathbf{e} / \mathbf{g}$ & 0.25 & 0.42 & 0.24 & 0.54 & 0.84 & 0.48 & 0.33 & 0.78 & 0.46 & 0.89 & 1.37 & 0.73 \\
\hline$\mu_{3}=\mathbf{f} / \mathbf{g}$ & 0.20 & 0.13 & 0.09 & 0.68 & 0.18 & 0.48 & 0.18 & 0.13 & 0.05 & 0.77 & 0.16 & 0.12 \\
\hline$\mu_{4}=\mathbf{f} / \mathbf{a}$ & 1.00 & 0.31 & 0.38 & 2.26 & 0.38 & 0.16 & 0.43 & 0.27 & 0.15 & 1.29 & 0.24 & 0.27 \\
\hline
\end{tabular}




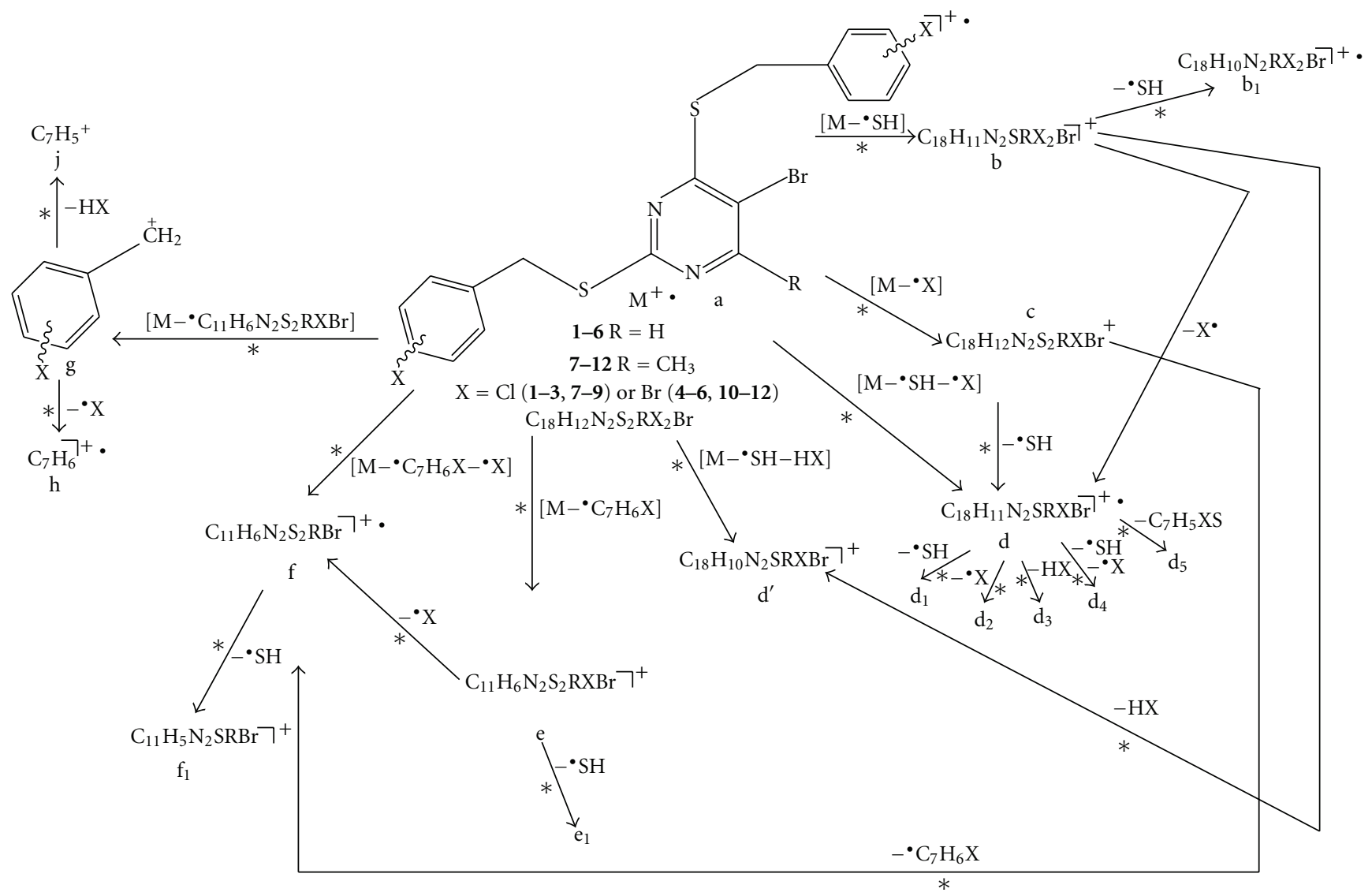

Scheme 1: Pathways of the EI mass fragmentation of the molecular ions $\mathrm{M}^{+} \cdot$ (a) of $\mathbf{1 - 1 2 .}$

and, for ion c $\left(\mathrm{C}_{18} \mathrm{H}_{13} \mathrm{~N}_{2} \mathrm{~S}_{2} \mathrm{BrCl}\right)$

435(70.9\%)/436(15.6\%)/437(100\%)

$$
/ 438(21.6 \%) / \mathbf{4 3 9}(\mathbf{3 2 . 8} \%) / 440(6.7 \%)
$$

/441(2.8\%)/442(0.4\%)/443(0.1\%),

so the abundances of ions at m/z 437 and 439 add up.

As can be seen from Scheme 1 and the data presented in Tables 1 and 2, the principal mass fragmentation pathways of 1-6 and 7-12 are similar but show differences in the abundances of important fragment ions. The fragmentation of molecular ion of the compounds studied 1-12 proceeds according to the same pattern (as can be seen from Figures 2(a) and 2(b), presenting EI mass spectra of two of the compounds studied as representative examples), in spite of the different substituents (chloro- or bromo-) and different positions (ortho or para) of halogen in the phenyl ring. Figure 2(a) shows the EI mass spectrum of 5-bromo-2,4di-o-chlorobenzylthio-6-methyluracil (compound 7) and Figure 2(b) the EI mass spectrum of 5-bromo-2,4-di- $p$ bromobenzylthio-6-methyluracil (compound 12). In the figures mentioned above, the main fragmentation features of $\mathrm{M}^{+\bullet}$ are clearly seen: both molecular ions easily lose ${ }^{\bullet} \mathrm{SH}$ and - $\mathrm{X}\left({ }^{\bullet} \mathrm{Cl}\right.$ or ${ }^{\bullet} \mathrm{Br}$, resp.) radicals as well as ${ }^{\bullet} \mathrm{CH}_{2} \mathrm{C}_{6} \mathrm{H}_{4} \mathrm{X}$, that is, the whole halobenzyl group. Other losses are loss of ${ }^{\bullet} \mathrm{SH}$ radical and neutral molecule $\mathrm{HX}\left(\mathrm{M}^{+\bullet}{ }^{\bullet} \mathrm{SH}-\mathrm{HCl}\right.$ or $\mathrm{M}^{+} \bullet_{-}$ - $\mathrm{SH}-\mathrm{HBr}$ ) and combined loss of halobenzyl radical and halogen from the other halobenzyl group in the molecule, however, it seems preferred that the loss of ${ }^{\bullet} \mathrm{Br}$ occurs rather from bromobenzyl derivatives and the loss of $\mathrm{HCl}$ occurs more likely from chlorobenzyl compounds. The same tendency is seen in the second step of fragmentation: the loss of $\mathrm{HCl}$ from the ions $\mathrm{g} \mathrm{m} / \mathrm{z} 125\left(\mathrm{CH}_{2} \mathrm{C}_{6} \mathrm{H}_{4} \mathrm{Cl}\right)$ gives daughter ion $\mathbf{j} \mathrm{m} / \mathrm{z} 89\left(\mathrm{C}_{7} \mathrm{H}_{5}{ }^{+}\right)$and loss of $\bullet \mathrm{Br}$ from the ions at $\mathrm{m} / \mathrm{z}$ 169/171 $\left(\mathrm{CH}_{2} \mathrm{C}_{6} \mathrm{H}_{4} \mathrm{Br}\right)$ yields ion $\mathbf{h}$ at $\mathrm{m} / \mathrm{z} 90$ $\left(\mathrm{C}_{7} \mathrm{H}_{6}{ }^{+\bullet}\right)$, which confirms a known fact that $\mathrm{HCl}$ formation is thermochemically favoured.

The $B / E=$ const linked scan spectrum of molecular ion of compound $\mathbf{1 2}$ (Figure I, see Supplementary Material available online at doi: 10.1155/2012/847676), with regard to the lowest mass isotope of bromine, that is, ${ }^{79} \mathrm{Br}$, presents the first step of fragmentation, that is, daughter ions formed through the dissociation of ion a $\left(\mathrm{C}_{19} \mathrm{H}_{15} \mathrm{~N}_{2} \mathrm{~S}_{2}{ }^{79} \mathrm{Br}_{3}, \mathrm{~m} / \mathrm{z}\right.$ 572). It indicates that most of important and abundant fragment ions, listed in Table 2, originate directly from the molecular ion. A comparative set of the EI mass spectra of 4-6 is presented in Figure II(A-C), Supplementary Material. Note different abundances of corresponding fragment ions and different retention times.

One of the essential processes of EI-MS decomposition of molecular ions $\mathbf{1 - 1 2}$ is the elimination of ${ }^{\bullet} \mathrm{SH}$ radicals. 


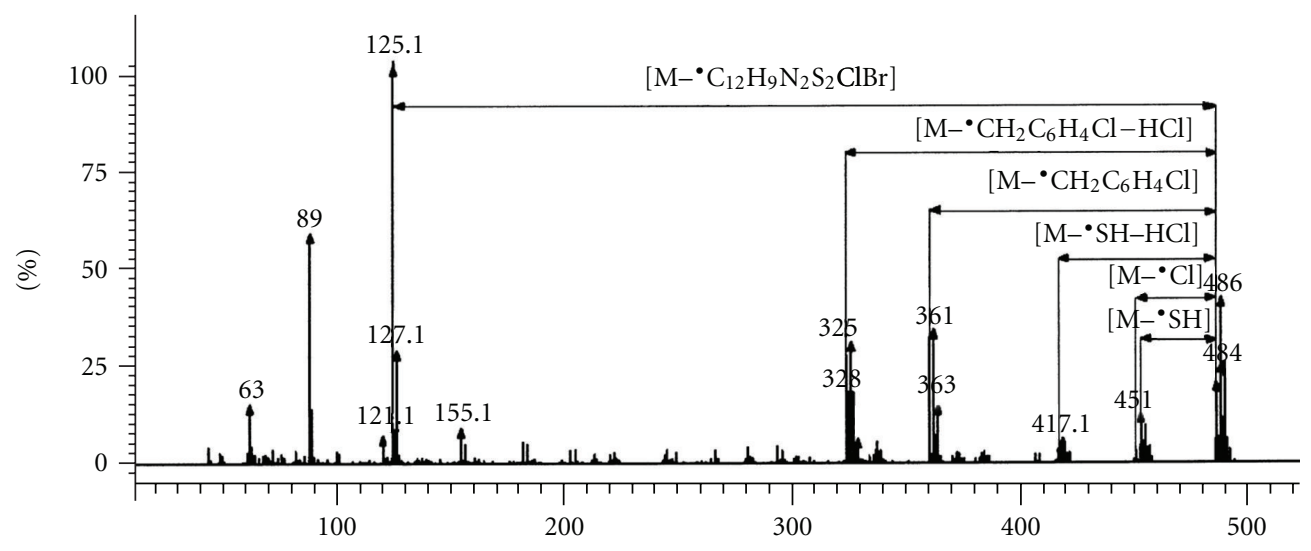

(a)

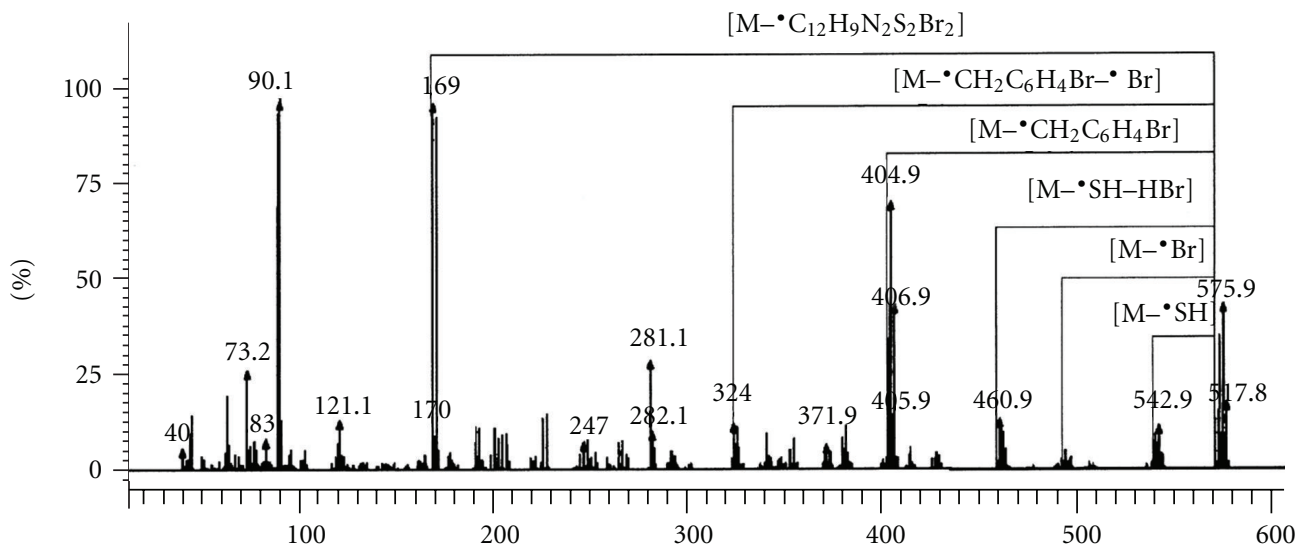

(b)

FIGURE 2: GC-EI mass spectra of: (a) 5-bromo-2,4-di-(ortho-chlorobenzylthio)-6-methyluracil 7, retention time 36.983 min; (b) 5-bromo2,4-di-(para-bromobenzylthio)-6-methyluracil 12, retention time $57.366 \mathrm{~min}$.

For the loss of $\cdot \mathrm{SH}$, a skeletal rearrangement is required which implies the formation of new carbon-carbon and carbon-nitrogen bonds. The ${ }^{\bullet} \mathrm{SH}$ elimination occurs directly from molecular ions a, leading to the even-electron fragment ions $\mathbf{b}$, as well as from the many fragment ions, giving second generation of daughter ions of low abundance in the EI mass spectrum. Fragment ions $\mathbf{b}$, that is, $\left[\mathrm{M}^{+}{ }_{-}\right.$ - $\mathrm{SH}$ ], are precursors of ions $\mathbf{d}$, created through the loss of - X from b. According to the metastable transition spectra $(B / E$ linked scan method), the loss of $\bullet \mathrm{SH}$ is a widespread process in the fragmentation routes of 1-12 because it takes place also for ions $\mathbf{c}, \mathbf{d}$, e, and $\mathbf{f}$, although the generated daughter ions $\mathbf{d}_{1}, \mathbf{e}_{1}, \mathbf{f}_{\mathbf{1}}$ are of low abundance and low significance for differentiation of isomers, and therefore they are not listed in Tables 1 and 2 . It should be mentioned that the loss of a sulfhydryl radical is common for aromatic thioethers [25] and is a characteristic feature of EI mass fragmentation of molecular ions of alkylthio-5bromo and alkoxycarbonylalkylthiouracils $[23,26]$ as well as 2-benzylthioorotic acids [27].

Molecular ions a decompose also with halogen radical elimination. In the EI mass spectra of compounds 4-6 and $\mathbf{9 - 1 2}$, the evident loss of $\boldsymbol{B}^{\mathrm{Br}}$ from molecular ion is seen, especially pronounced for the ortho isomers 4 and 10. The bromine loss can be noticed also in the further steps of fragmentation, for example, the $B / E=$ const linked scan spectrum of ion $\mathrm{c}$ of compound $\mathbf{1 2}$ presents intense - $\mathrm{Br}$ elimination. It remains unknown if there is a loss of bromine radical from the uracil or phenyl ring. Analysis of EI mass spectra of $\mathbf{1 - 3}$ and $\mathbf{7 - 9}$, where the $\left[\mathrm{M}-{ }^{\bullet} \mathrm{Br}\right]$ ions are almost completely absent, indicates that bromine originates from benzyl moiety. Analogously, ions e of 10-12, that is, $\mathrm{C}_{12} \mathrm{H}_{9} \mathrm{~N}_{2} \mathrm{~S}_{2} \mathrm{Br}_{2}$ lose bromine radical giving $\mathbf{f}$, but ions e of $7-$ 9 lose ${ }^{\circ} \mathrm{Cl}$ not ${ }^{\bullet} \mathrm{Br}$. It means that in this series of uracil derivatives bromine radicals are more easily abstracted from phenyl than from pyrimidine ring and the $\mathrm{X}-\mathrm{C}_{\mathrm{sp}^{2}}$ bond in phenyl ring is more prone to cleave than in heteroaromatic one. This is the difference between disubstituted 5-bromodithiouracils and monosubstituted 5-bromothiouracils. It was mentioned earlier that ${ }^{\bullet} \mathrm{Br}$ loss from $\mathrm{C}-5$ position of pyrimidine ring is characteristic of many bromouracil and bromothiouracil derivatives and that ${ }^{\circ} \mathrm{Br}$ radical elimination is more intense for 4-thio- than for 2-thioderivatives [23, 26]. For molecular ions of 5-bromo-2,4-di-o- ( $m$ - and $p$-)chloro- (bromo-) benzylthiouracils, the elimination of bromine radical from position 5 of pyrimidine ring does not occur in the EI-MS 
<smiles>[R3]c1nc([R3])c(Br)c(=O)[nH]1</smiles><smiles>[R9]c1[nH]c(=O)nc([13CH3])c1Br</smiles>

I

(a)<smiles>[R3]c1nc([R2])c(Br)c([R19])n1</smiles>

III

(c)

FIGURE 3: Tautomeric forms of S-substituted 2-thio-5-bromouracils (I), 4-thio-5-bromouracils (II), and 2,4-dithio-5-bromouracils (III).

conditions. It is hard to rationalize why the ${ }^{\bullet} \mathrm{Br}$ loss from $\mathrm{C}$ 5 is easy in 4-thiouracil derivatives, more difficult in 2-thio, and very difficult in 2,4-dithio compounds. The structure of all the compounds mentioned is similar, and the main difference seems to be their three distinct tautomeric forms. Compounds 1-12, unlike the mono S-substituted 2-thiouracils or 4-thiouracils, appear to be in fully aromatic form of pyrimidine ring (Figure 3, structure III), as the only possible for di-S-substituted dithiouracils. It should be mentioned that $\mathrm{C}(5)$-Br cleavage was also not observed for 2,4-dialkoxy5-bromouracils [28], which possess similar six-electron conjugated $\pi$-system as the compounds studied herein (1-12).

The combined loss of $\cdot \mathrm{SH}$ and $\cdot \mathrm{X}$ radicals from molecular ions 1-12 leads to the odd-electron ions d $\mathrm{C}_{18} \mathrm{H}_{12} \mathrm{~N}_{2} \mathrm{~S}_{2} \mathrm{RX}_{2} \mathrm{Br}^{+} \bullet$. Ions $\mathbf{d}$ are also created stepwise, from ions $\mathbf{c}$ through the loss of $\bullet \mathrm{SH}$ and from ions $\mathbf{b}$ through the elimination of $\cdot \mathrm{X}$ radicals. All the fragmentation routes are confirmed by $B / E=$ const linked scan spectra.

The main fragmentation pathways of odd-electron molecular ions $\mathrm{M}^{+}$(a) of 1-12 involve also cleavages of the bonds between the sulfur atoms and carbon $\left(\mathrm{sp}^{3}\right)$ atoms of the benzyl substituent with the ejection of ${ }^{\bullet} \mathrm{C}_{7} \mathrm{H}_{6} \mathrm{X}(\mathrm{X}=\mathrm{Cl}$, $\mathrm{Br})$ radicals. This is a typical inductive cleavage producing the even-electron fragment ions e. The complementary cleavage involving the elimination of ${ }^{\circ} \mathrm{C}_{11} \mathrm{H}_{6} \mathrm{~N}_{2} \mathrm{~S}_{2} \mathrm{BrXR}$ radicals creates the even-electron ions $\mathbf{g}\left(\mathrm{C}_{7} \mathrm{H}_{6} \mathrm{X}^{+}\right)$. It should be pointed out that the peaks of the even-electron fragment ions $\mathbf{g}$ are the base peaks of the EI mass spectra of $\mathbf{1 - 9}$. So it is clear that, during the simple cleavage of the $\mathrm{C}_{\mathrm{sp}^{3}}-\mathrm{S}$ bonds of the benzylthio substituent, the positive charge is stabilized more efficiently on the halobenzyl fragment. Ions $\mathbf{g}$ undergo further fragmentation through the elimination of ${ }^{\bullet} \mathrm{X}$ radical or the neutral loss of HX molecule to the odd-electron fragment ions $\mathbf{h}\left(\mathrm{C}_{7} \mathrm{H}_{6}{ }^{+\bullet}\right)$ and even-electron fragment ions $\mathbf{j}\left(\mathrm{C}_{7} \mathrm{H}_{5}{ }^{+}\right)$, respectively. Ions $\mathbf{c}$ decompose further losing sulfhydryl $(\bullet \mathrm{SH})$, substituted benzyl $\left({ }^{\bullet} \mathrm{C}_{7} \mathrm{H}_{6} \mathrm{X}\right)$, or halogen $\left({ }^{\bullet} \mathrm{X}\right)$ radicals. Odd-electron fragment ions $\mathbf{d}$ undergo the elimination of $\bullet \mathrm{SH},{ }^{\bullet} \mathrm{X}$ ( or $\mathrm{HX}$ ), ${ }^{\bullet} \mathrm{SH}$ and ${ }^{\bullet} \mathrm{X}$ sequentially as well as they lose neutral fragments $\mathrm{C}_{7} \mathrm{H}_{5} \mathrm{SX}$. The created daughter ions are of low abundance (and that is why they are not listed in Tables 1 and 2).

The differences in the fragmentations within each of the four sets of isomeric compounds within the series of 5-bromo-2,4-di-o- ( $m$ - and $p$-) chloro- (bromo-)benzylthiouracils 1-6 and 5-bromo-2,4-di-o- $(m$ - and $p$-) chloro- (bromo-) benzylthio-6-methyluracils 7-12 were expressed quantitatively by comparing the calculated values of the coefficients $\mu$, that is, ratios of the relative abundances (RA) of chosen ions. Relative abundance RA is defined as \% of the abundance of a given ion relative to that of the most abundant ion in the spectrum, whose abundance is assumed as $100 \%$. In this work, we decided to refer relative abundances of important ions: a (molecular ions, $\left.\mathrm{M}^{+\bullet}\right)$ and $\mathbf{e}\left(\mathrm{M}^{+\bullet}-{ }^{\bullet} \mathrm{CH}_{2} \mathrm{C}_{6} \mathrm{H}_{4} \mathrm{X}\right)$ to the relative abundances of very stable ions $\mathbf{g}$, that is, halobenzyl cations (or, equivalently, halotropylium ions). We have also observed that ions $\mathbf{f}$ are the most abundant for all ortho isomers of compounds $\mathbf{1 - 1 2}$, that is, for compounds $\mathbf{1}$, 4, 7, and 10 (Tables 1 and 2), and that is why we defined two coefficients based on the $\mathbf{f}$ ions: $\mathbf{f} / \mathbf{g}$ and $\mathbf{f} / \mathbf{a}$.

The $\mu$ coefficients, used for isomers studied discrimination, are defined as follows:

$$
\begin{aligned}
& \mu_{1}=\% \text { RA a/\%RA g, } \\
& \mu_{2}=\% \text { RA e/ } \% \text { RA g, } \\
& \mu_{3}=\% \text { RA f } / \% \text { RA g, } \\
& \mu_{4}=\% \text { RA f } / \% \text { RA a. }
\end{aligned}
$$

In each set of three isomers (1-3, 4-6, 7-9, 10-12) meta isomer can be distinguished from ortho and para by the highest value of $\mu_{1}$ and $\mu_{2}$. For all dithiouracils derivatives studied 1-6, the values of $\mu_{1}$ are decreasing in the order meta $>$ para $>$ ortho, and, for the substituted dithio-6methyluracils 7-12, descending order of $\mu_{1}$ is meta $>$ ortho $>$ para.

The coefficient $\mu_{2}$ is evidently the highest for all meta isomers and comparable for ortho and para. So one can describe the order of $\mu_{2}$ values as:

$$
\mu_{2} \text { meta } \gg \mu_{2} \text { ortho } \approx \mu_{2} \text { para 1-12. }
$$

The conclusion is that $\mu_{1}$ and $\mu_{2}$ are sufficient for distinction isomers meta from ortho and para but insufficient for discrimination between para and ortho. However, the ortho isomers can be distinguished from the others by the highest value of $\mu_{3}$ and $\mu_{4}$.

It should be emphasized that compounds 1-12 are thermally stable under the mass spectrometric conditions 
TABLE 4: Retention times of 5-bromo-2,4-di-o - ( $m$ - and $p$-) chloro- (bromo-)benzylthiouracils 1-12.

\begin{tabular}{lcccc}
\hline Compound name & $\begin{array}{c}\text { Compound } \\
\text { number }\end{array}$ & Chemical formula & $\begin{array}{c}\text { Molecular } \\
\text { weight } \\
\text { (average) }\end{array}$ & $\begin{array}{c}\text { Retention } \\
\text { time (min) }\end{array}$ \\
\hline 5-bromo-2,4-di-o-chloro-benzylthiouracil & $\mathbf{1}$ & $\mathrm{C}_{18} \mathrm{H}_{13} \mathrm{~N}_{2} \mathrm{~S}_{2} \mathrm{Cl}_{2} \mathrm{Br}$ & 472.256 & 34.52 \\
5-bromo-2,4-di-m-chloro-benzylthiouracil & $\mathbf{2}$ & $\mathrm{C}_{18} \mathrm{H}_{13} \mathrm{~N}_{2} \mathrm{~S}_{2} \mathrm{Cl}_{2} \mathrm{Br}$ & 472.256 & 35.21 \\
5-bromo-2,4-di-p-chloro-benzylthiouracil & $\mathbf{3}$ & $\mathrm{C}_{18} \mathrm{H}_{13} \mathrm{~N}_{2} \mathrm{~S}_{2} \mathrm{Cl}_{2} \mathrm{Br}$ & 472.256 & 37.86 \\
5-bromo-2,4-di-o-bromo-benzylthiouracil & $\mathbf{4}$ & $\mathrm{C}_{18} \mathrm{H}_{13} \mathrm{~N}_{2} \mathrm{~S}_{2} \mathrm{Br}_{3}$ & 561.159 & 45.71 \\
5-bromo-2,4-di- $m$-bromobenzylthiouracil & $\mathbf{5}$ & $\mathrm{C}_{18} \mathrm{H}_{13} \mathrm{~N}_{2} \mathrm{~S}_{2} \mathrm{Br}_{3}$ & 561.159 & 47.66 \\
5-bromo-2,4-di-p-bromobenzylthiouracil & $\mathbf{6}$ & $\mathrm{C}_{18} \mathrm{H}_{13} \mathrm{~N}_{2} \mathrm{~S}_{2} \mathrm{Br}_{3}$ & 561.159 & 53.50 \\
5-bromo-2,4-di-o-chlorobenzylthio-6-methyluracil & $\mathbf{7}$ & $\mathrm{C}_{19} \mathrm{H}_{15} \mathrm{~N}_{2} \mathrm{~S}_{2} \mathrm{Cl}_{2} \mathrm{Br}$ & 486.283 & 36.98 \\
5-bromo-2,4-di- $m$-chlorobenzylthio-6-methyluracil & $\mathbf{8}$ & $\mathrm{C}_{19} \mathrm{H}_{15} \mathrm{~N}_{2} \mathrm{~S}_{2} \mathrm{Cl}_{2} \mathrm{Br}$ & 486.283 & 37.44 \\
5-bromo-2,4-di-p-chloro benzylthio-6-methyluracil & $\mathbf{9}$ & $\mathrm{C}_{19} \mathrm{H}_{15} \mathrm{~N}_{2} \mathrm{~S}_{2} \mathrm{Cl}_{2} \mathrm{Br}$ & 486.283 & 40.13 \\
5-bromo-2,4-di-o-bromo benzylthio-6-methyluracil & $\mathbf{1 0}$ & $\mathrm{C}_{19} \mathrm{H}_{15} \mathrm{~N}_{2} \mathrm{~S}_{2} \mathrm{Br}_{3}$ & 575.186 & 49.49 \\
5-bromo-2,4-di- $m$-bromobenzylthio-6-methyluracil & $\mathbf{1 1}$ & $\mathrm{C}_{19} \mathrm{H}_{15} \mathrm{~N}_{2} \mathrm{~S}_{2} \mathrm{Br}_{3}$ & 575.186 & 51.06 \\
5-bromo-2,4-di- $p$-bromobenzylthio-6-methyluracil & $\mathbf{1 2}$ & $\mathrm{C}_{19} \mathrm{H}_{15} \mathrm{~N}_{2} \mathrm{~S}_{2} \mathrm{Br}_{3}$ & 575.186 & 57.27 \\
\hline
\end{tabular}

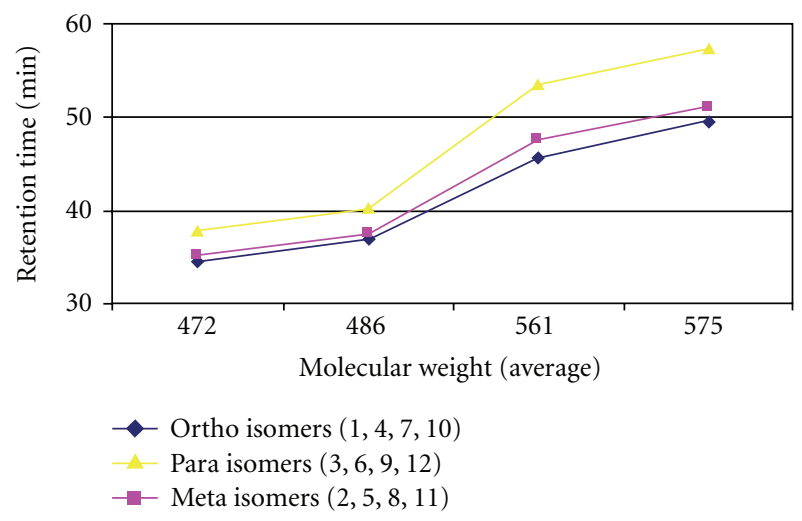

Figure 4: GC retention times depending on molecular weight of compounds studied and location of substituents in the aromatic ring.

used and that the repeatability error of the values $\mu$ has been confirmed at the level of $1-3 \%$; the interday reproducibility of these abundances ratios was similar (error about 3\%). In each determination, three scans were averaged to obtain statistically adequate results.

All the compounds 1-12 differ also in gas chromatography retention times (RT, Table 4). It is clearly seen that RT depends on molecular masses of separate compounds and their values for 5-bromo-2,4-di-(bromobenzylthio)uracils (4-6, 10-12) are higher than for respective chloroderivatives (1-3, 7-9) and that RT values for 5-bromo-2,4-di(halobenzylthio)-6-methyluracils (7-12) are slightly higher than for respective 5-bromo-2,4-di-(halobenzylthio)uracils without methyl group in position $6(\mathbf{1 - 6})$. There is close relationship between retention time and polarity of compound chromatographed, as well. This dependence is regular in the group of compounds studied herein: in each set of isomers, that is, chemical species with the same molecular mass, the shortest retention times possess ortho isomers and the longest para isomers (Figure 4).

\section{Conclusions}

The present study has demonstrated that the analysis of EIinduced mass spectra of 5-bromo-2,4-di- $o$ - ( $m$ - and $p-)$ chloro- (bromo-)benzylthiouracils (1-6) and 6-methyluracils (7-12) is a useful method for distinction of structural isomers. The differentiation of the ortho $(\mathbf{1}, \mathbf{4}, \mathbf{7}, \mathbf{1 0})$, meta $(2$, $5,8,11$ ), and para $(3,6,9,12)$ chloro (bromo) substituted in the benzyl substituent isomers of this series of compounds is possible on the basis of comparison of their EI mass spectra coefficients $\mu$ (i.e., ratios of the relative abundances RA of chosen ions) according to the methodology published by us earlier [26, 27]. It should be mentioned that the distinction of ortho $(1,4,7,10)$, meta $(2,5,8,11)$, and para $(3,6,9,12)$ chloro (bromo) substituted isomers of $\mathbf{1 - 1 2}$ is also possible on the basis of the differences in their retention times by gas chromatography.

\section{References}

[1] L. S. Goodman and A. Gilman, Eds., The Pharmacological Basis of Therapeutics, Macmillan, New York, NY, USA, 5th edition, 1975.

[2] W. Saenger, in Principles of Nucleic Acids Structure, SpringerVerlag: New York, Berlin, Heidelberg, Tokyo, 1984, Chapter 7.

[3] W. Saenger and D. Suck, "The relationship between hydrogen bonding and base stacking in crystalline 4-thiouridine derivatives," European Journal of Biochemistry, vol. 32, no. 3, pp. 473478, 1973.

[4] U. Thewalt and C. E. Bugg, "Effects of sulfur substituents on base stacking and hydrogen bonding. The crystal structure of 6-thioguanosine monohydrate," Journal of the American Chemical Society, vol. 94, no. 25, pp. 8892-8898, 1972.

[5] A. G. Lezius and K. H. Scheit, "Enzymatic synthesis of DNA with 4-thio-thymidine triphosphate as substitute for dTTP," European Journal of Biochemistry, vol. 3, no. 1, pp. 85-94, 1967.

[6] E. M. Gottschalk, E. Kopp, and A. G. Lezius, "A synthetic DNA with unusual base-pairing," European Journal of Biochemistry, vol. 24, no. 1, pp. 168-182, 1971. 
[7] K. H. Scheit and E. Gaertner, "Die Polymerization von 4Thiouridin-5'-diphosphat und 4-thiothymidin-5'-diphosphat durch Polynucleotidphosphorylase aus Micrococcus lysodeikticus," Biochimica et Biophysica Acta, vol. 182, no. 1, 1969.

[8] E. Freese, "The specific mutagenic effect of base analogues on phage T4," Journal of Molecular Biology, vol. 1, no. 2, pp. 87$105,1959$.

[9] E. Freese, "The difference between spontaneous and baseanalogue induced mutations of phage T4," Proceedings of the National Academy of Sciences of the United States of America, vol. 45, no. 4, pp. 622-633, 1959.

[10] S. Y. Wang, "Pyrimidine bimolecular photoproducts," in Photochemistry and Photobiology of Nucleic Acids, vol. 1, pp. 295-326, Academic Press, New York, NY, USA, 1976.

[11] M. Imaizumi, F. Kano, and S. Sakata, "Novel uracil derivatives: newly synthesized centrally acting agents," Chemical and Pharmaceutical Bulletin, vol. 40, no. 7, pp. 1808-1813, 1992.

[12] I. W. Althaus, K.-C. Chou, R. J. Lemay et al., "The benzylthiopyrimidine U-31,355, a potent inhibitor of HIV-1 reverse transcriptase," Biochemical Pharmacology, vol. 51, no. 6, pp. 743-750, 1996.

[13] R. A. Nugent, S. T. Schlachter, M. J. Murphy et al., "Pyrimidine thioethers: a novel class of HIV-1 reverse transcriptase inhibitors with activity against BHAP-resistant HIV," Journal of Medicinal Chemistry, vol. 41, no. 20, pp. 3793-3803, 1998.

[14] P. Crain, T. Hasizume, and J. A. McCloskey, in Biological Mass Spectrometry, ed. by A. L. Burlingame and J. A. McCloskey, 671-692, Elsevier, Amsterdam [1990].

[15] K. Schram, "Mass spectrometry of nucleic acid components," in Biological Application of Mass Spectrometry, C. H. Suelter and J. T. Watson, Eds., pp. 203-288, John Wiley, New York, NY, USA, 1990.

[16] J. A. McCloskey, in Mass Spectrometry in the Health and Life Sciences, ed. by A. L. Burlingame and N. Castagnoli Jr., Elsevier Amsterdam [1985].

[17] J. A. McCloskey, in Mass Spectrometry in Biomedical Research, ed. by S. J. Gaskell, Wiley, New York [1986].

[18] J. Garin, J. Orduna, J. M. Royo, A.-M. Le Quere, and H. Muller, "Differentiation of isomeric sulfur heterocycles by electron ionization mass spectrometry: 1,4-dithiins, 1,4-dithiafulvenes nad their analogues tetrathianaphtalenes, tetrathiafulvalenes and tetrathiapentalenes," Rapid Communications in Mass Spectrometry, vol. 17, no. 6, pp. 547-552, 2003.

[19] V. Ovcharenko, M. Rzadkowska, T. Tkaczynski, D. Matosiuk, and K. Pihlaja, "Electron impact mass spectra of substituted 1-aryl-2-arylsulphonylamino- $\delta 2$-imidzazolines," Rapid Communications in Mass Spectrometry, vol. 11, no. 9, pp. 10431045, 1997.

[20] E. Wyrzykiewicz and Z. Nowakowska, "Mass spectrometry of thio analogues of pyrimidine bases: correlation of the intensities of the $\mathrm{M}^{+}$and selected fragment ions of $o$ - $(m$ - and $p$ - $)$ substituted benzylthiouracils," Journal of Mass Spectrometry, vol. 30, no. 2, pp. 269-274, 1995.

[21] E. Wyrzykiewicz and G. Bartkowiak, "Mass spectrometry of thio analogues of pyrimidine bases: Correlation of the intensities of the $\mathrm{M}^{+\bullet}$ and the $\left[\mathrm{M}-{ }^{-} \mathrm{SH}\right]^{+}$ions of 2-alkylthiouracils," Organic Mass Spectrometry, vol. 27, no. 12, pp. 1377-1380, 1992.

[22] G. Bartkowiak, "Differentiation of 2-alkylthioorotic acids, methyl and ethyl 2-alkylthioorotates and hydrazides of 2alkylthioorotic acids by using electron ionization mass spectra," European Journal of Mass Spectrometry, vol. 14, no. 1, pp. 27-35, 2008.
[23] J. Wybieralska, "Electron impact induced mass spectral study of 2- and 4- ethoxycarbonylalkylthio-5-bromo-6-methyluracils," Rapid Communications in Mass Spectrometry, vol. 14, no. 12, pp. 1074-1076, 2000.

[24] G. Bartkowiak, E. Wyrzykiewicz, G. Schroeder, A. Walkowiak, A. Szponar, and I. Pawlak, "Thio analogues of pyrimidine bases: Syntheses and spectral study of new potentially biologically active 2,4-di-ortho-(meta- and para-) bromo- (chloro and nitro)-benzylthio-5-bromouracils (and 6-methyluracils)," Phosphorus, Sulfur and Silicon and the Related Elements, vol. 185, no. 7, pp. 1429-1436, 2010.

[25] F. W. McLafferty and F. Turecek, Interpretation of Mass Spectra, University Science Books, Mill Valley, Calif, USA, 4th edition, 1993.

[26] G. Bartkowiak, "Electron ionization induced mass spectral study of 2-alkylthio- and 4-alkykthio-5-bromouracils," Rapid Communications in Mass Spectrometry, vol. 19, no. 9, pp. 1207-1212, 2005.

[27] E. Wyrzykiewicz and G. Bartkowiak, "EIMS and C-13 NMR study of new ortho (meta and para) substituted derivatives of 2-benzylthioorotic acids," Polish Journal of Chemistry, vol. 69, no. 4, p. 566, 1995.

[28] A. S. Plaziak, H. Wójtowicz-Rajchel, and K. Golankiewicz, "Mass spectrometry of 2,4-dialkoxy-5-bromopyrimidines," Polish Journal of Chemistry, vol. 72, no. 4, pp. 719-724, 1998. 


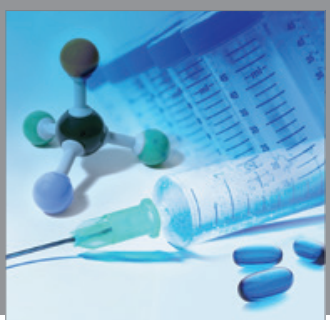

International Journal of

Medicinal Chemistry

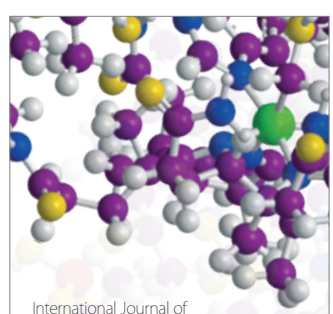

Carbohydrate Chemistry

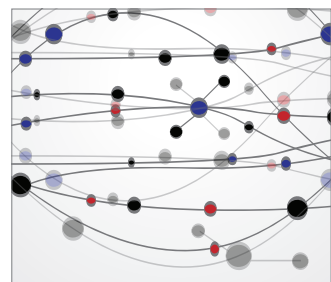

The Scientific World Journal
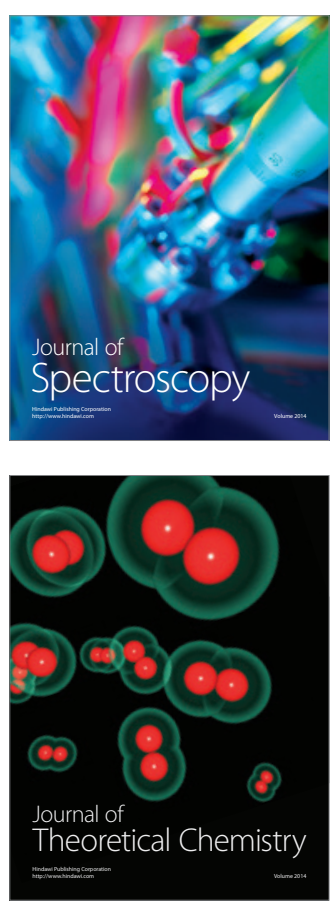
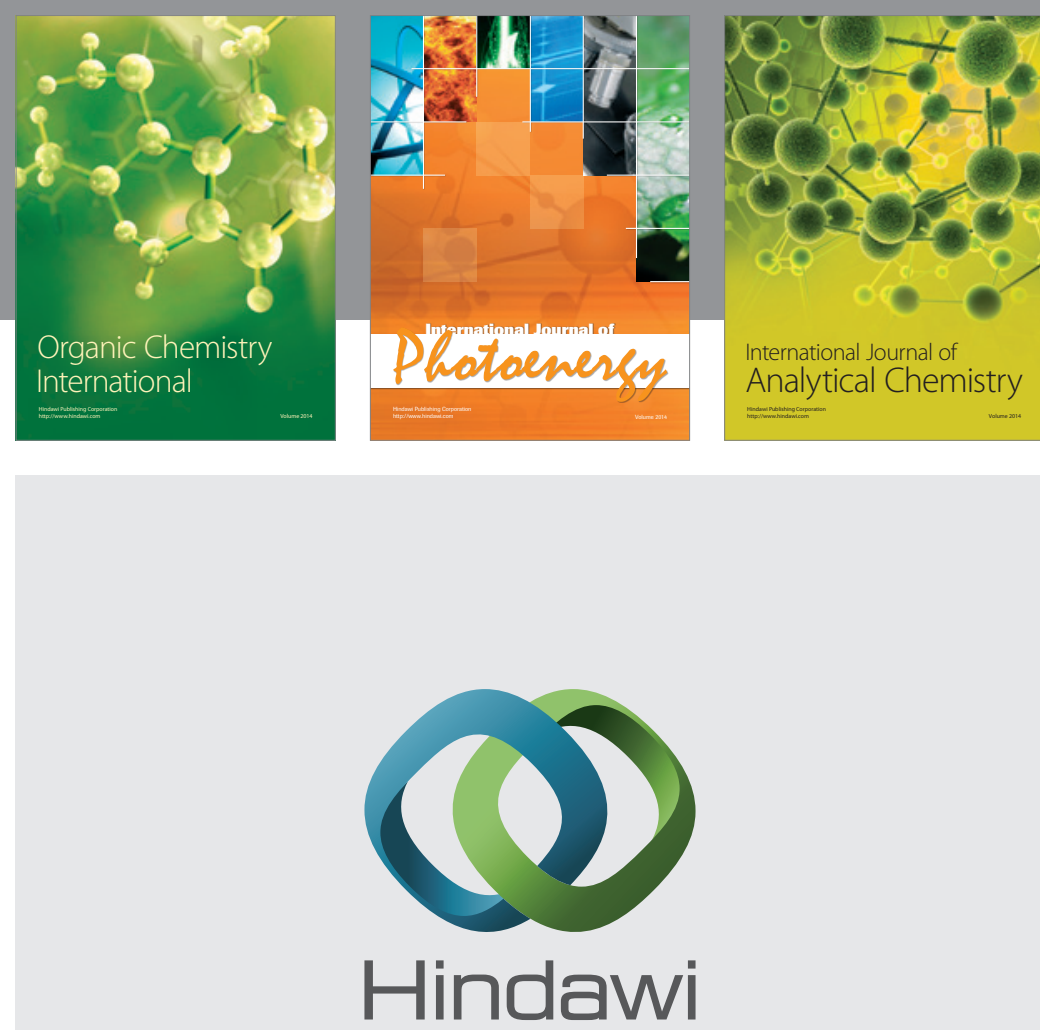

Submit your manuscripts at

http://www.hindawi.com
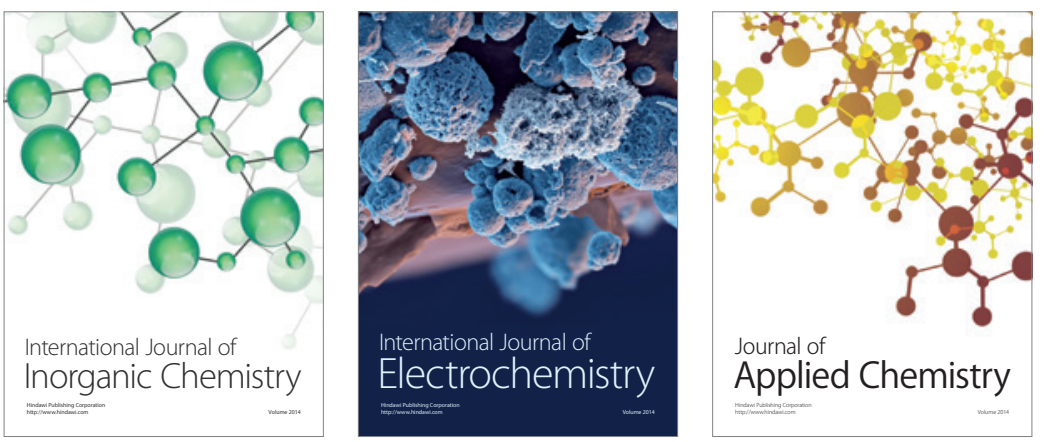

Journal of

Applied Chemistry
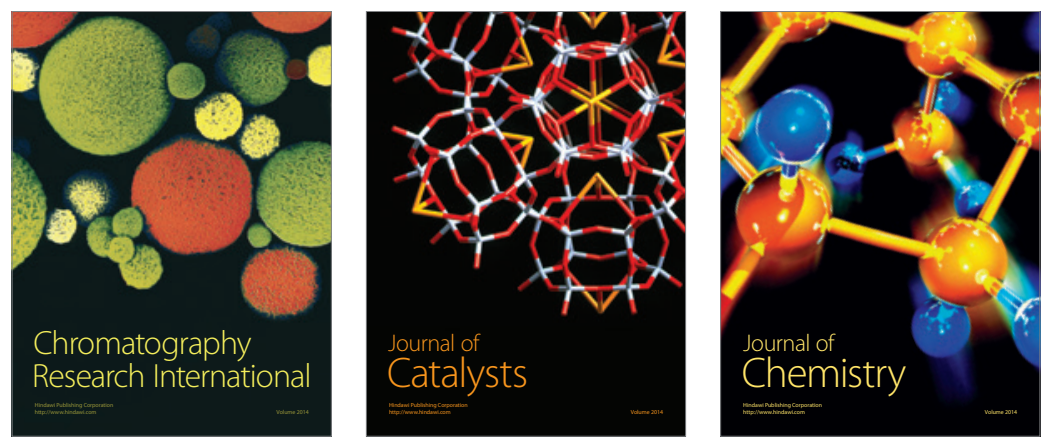
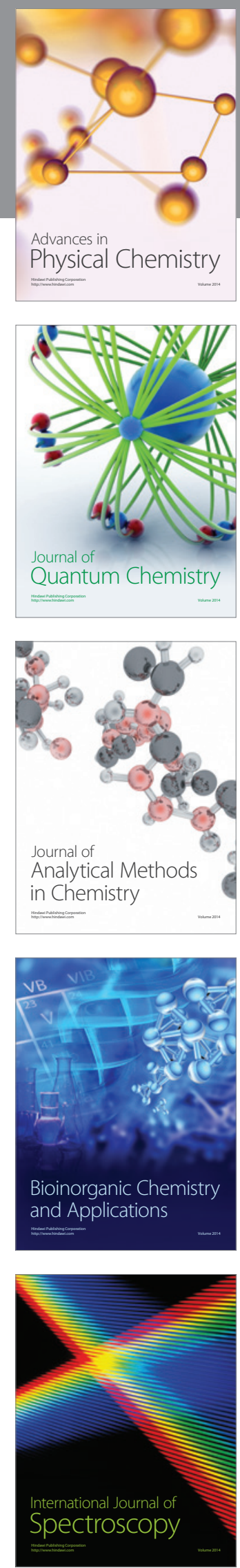